\title{
The influence of short-term heat acclimation with permissive dehydration on temperate exercise performance in highly trained athletes
}

\author{
Rebecca Neal, Jo Corbett ${ }^{*}$, Heather Massey, Michael J Tipton \\ From 15th International Conference on Environmental Ergonomics (ICEE XV) \\ Portsmouth, UK. 28 June - 3 July 2015
}

\begin{abstract}
Introduction
Long-term ( $\geq 10$ day) heat acclimation (HA) has been shown to be ergogenic under cool ambient conditions [1]. Potential mechanisms underpinning the ergogenic effects of long-term HA include increased maximal oxygen uptake, possibly mediated by plasma volume (PV) expansion and an increased maximal cardiac output [1], as well as reduced physiological strain through improved thermoregulation [2]. Recently, short-term (5 day) HA with restricted fluid intake (STHADe) has been shown to augment PV expansion and accelerate HA relative to euhydrated HA [3]; performance improvements in the heat have been documented in highly-trained men following this regime [4]. This study examined the ergogenic effect of STHADe on exercise in a temperate environment.
\end{abstract}

\section{Methods}

Ten highly-trained male cyclists and triathletes (Mean[SD] age 24[4] years; height 1.76[0.04] m; mass $70.9[7.3] \mathrm{kg}$; maximal oxygen uptake $\left[\mathrm{VO}_{2 \mathrm{max}}\right]: 63.3[4.0] \mathrm{mL} \cdot \mathrm{kg}^{-1} \cdot \mathrm{min}^{-1}$; peak power output [PPO]: 385[40] W; training: 10[3] hours.week $^{-1}$ ) underwent a STHADe programme consisting of 5-consecutive days of exercise $\left(90\right.$ mins.day $\left.^{-1}\right)$ under isothermic heat strain (target rectal temperature $\left[T_{r e}\right]$ of $\left.38.5-38.9{ }^{\circ} \mathrm{C}\right)$ in a hot environment $\left(T_{a m b}=40{ }^{\circ} \mathrm{C}, 50 \%\right.$ rh). During HA sessions, and for 30 minutes after, participants did not receive any fluids. Euhydrated heat stress tests (HST) were completed the day before and the day after the STHADe (60 mins cycling at $35 \%$ PPO, $T_{a m b}=$ $\left.40{ }^{\circ} \mathrm{C}, 50 \% \mathrm{rh}\right)$. A graded exercise test (GXT) for determination of blood lactate threshold (LT), $\mathrm{VO}_{2 \max }$ and PPO as well as a $20 \mathrm{~km}$ self-paced time trial (TT) (on a separate

\footnotetext{
* Correspondence: jo.corbett@port.ac.uk

Extreme Environments Laboratory, Department of Sport and Exercise

Science, University of Portsmouth, Portsmouth, UK
}

day) were performed in a temperate environment $\left(22^{\circ} \mathrm{C}\right.$, $50 \% \mathrm{rh}$ ) pre- and post-STHADe.

\section{Results}

STHADe significantly reduced rectal $\left(\Delta T_{r e}=-0.2[0.2]^{\circ} \mathrm{C}\right)$ and mean body temperature $\left(\Delta T_{\mathrm{b}}=-0.2[0.2]{ }^{\circ} \mathrm{C}\right)$, heart rate $\left(\Delta f_{\mathrm{c}}=-7[7] \mathrm{b} \cdot \mathrm{min}^{-1}\right)$ and perceived exertion, and augmented local and whole body sweat rate $($ all $P<0.05)$ during the HST; no clear expansion of plasma volume was seen $(\Delta \mathrm{PV}=1.2[8.0] \%, P=0.64)$. Constant workload exercise in a temperate environment indicated that STHADe reduced resting and exercising mean skin temperature $\left(T_{\mathrm{sk}}\right), T_{r e}, T_{\mathrm{b}}$ and $f_{\mathrm{c}}($ all $P<0.05)$ under these conditions. Performance trials in a temperate environment suggest that PPO $(\Delta=6[7] \mathrm{W})$ and LT $(\Delta=16[17] \mathrm{W})$ in the GXT were improved $(P<0.05)$ following STHADe but $\mathrm{VO}_{2 \max }$ and TT performance were not significantly affected $(P>0.05)$ although there was a trend for a higher mean power $(P=0.06)$.

\section{Discussion}

These data show typical markers of HA during exercise in the heat and that STHADe is effective at reducing thermal and cardiovascular strain under temperate conditions. The lack of $\triangle \mathrm{PV}$ may be due to high baseline blood volumes in this highly trained cohort, or higher daily dehydration levels than in previous studies [3]. Although there was no effect on TT performance, other indicators of performance such as PPO were improved. These ergogenic effects might occur by thermal effects, such as a reduced 'physiological cost' of thermoregulation, or non-thermal effects, such as an improved power at LT. 


\section{Conclusion}

STHADe induced favourable thermal, thermoregulatory, physiological and cardiovascular responses to exercise in hot and temperate environments in highly-trained athletes. It may be necessary to extend the duration of HA to fully elucidate the ergogenic benefit in temperate environments.

\section{References}

1. Lorenzo $\mathrm{S}$, et al: Heat acclimation improves exercise performance. J Appl Physiol 2010, 109:1140-1147.

2. Corbett J, et al: Adaptation to heat and exercise performance under cooler conditions: a new hot topic. Sport Med 2014, 44(10):1323-31.

3. Garrett AT, et al: Short-term heat acclimation is effective and may be enhanced rather than impaired by dehydration. Am J Hum Bio 2014, 26:311-320.

4. Garrett AT, et al: Effectiveness of short-term heat acclimation for highly trained athletes. Eur J Appl Physiol 2012, 112:1827-1837.

doi:10.1186/2046-7648-4-S1-A109

Cite this article as: Neal et al:: The influence of short-term heat acclimation with permissive dehydration on temperate exercise performance in highly trained athletes. Extreme Physiology \& Medicine 2015 4(Suppl 1):A109.

\section{Submit your next manuscript to BioMed Central} and take full advantage of:

- Convenient online submission

- Thorough peer review

- No space constraints or color figure charges

- Immediate publication on acceptance

- Inclusion in PubMed, CAS, Scopus and Google Scholar

- Research which is freely available for redistribution

Submit your manuscript at www.biomedcentral.com/submit 